\title{
RESEARCH
}

Open Access

\section{Fluoxetine attenuates neuroinflammation in early brain injury after subarachnoid hemorrhage: a possible role for the regulation of TLR4/MyD88/NF-KB signaling pathway}

Fu-yi Liu, Jing Cai, Chun Wang, Wu Ruan, Guo-ping Guan, Hai-zhou Pan, Jian-ru Li, Cong Qian, Jing-sen Chen, Lin Wang and Gao Chen *i)

\begin{abstract}
Background: Neuroinflammation is closely associated with functional outcome in subarachnoid hemorrhage (SAH) patients. Our recent study demonstrated that fluoxetine inhibited NLRP3 inflammasome activation and attenuated necrotic cell death in early brain injury after SAH, while the effects and potential mechanisms of fluoxetine on neuroinflammation after SAH have not been well-studied yet.

Methods: One hundred and fifty-three male SD rats were subjected to the endovascular perforation model of $\mathrm{SAH}$. Fluoxetine $(10 \mathrm{mg} / \mathrm{kg})$ was administered intravenously at $6 \mathrm{~h}$ after SAH induction. TAK-242 $(1.5 \mathrm{mg} / \mathrm{kg})$, an exogenous TLR4 antagonist, was injected intraperitoneally $1 \mathrm{~h}$ after SAH. SAH grade, neurological scores, brain water content, Evans blue extravasation, immunofluorescence/TUNEL staining, quantitative real-time polymerase chain reaction (qRT-PCR), and western blot were performed.

Results: Fluoxetine administration attenuated BBB disruption, brain edema, and improved neurological function after $\mathrm{SAH}$. In addition, fluoxetine alleviated the number of Iba-1-positive microglia/macrophages, neutrophil infiltration, and cell death. Moreover, fluoxetine reduced the levels of pro-inflammatory cytokines, downregulated the expression of TLR4 and MyD88, and promoted the nuclear translocation of NF-KB p65, which were also found in rats with TAK-242 administration. Combined administration of fluoxetine and TAK-242 did not enhance the neuroprotective effects of fluoxetine.
\end{abstract}

Conclusion: Fluoxetine attenuated neuroinflammation and improved neurological function in SAH rats. The potential mechanisms involved, at least in part, TLR4/MyD88/NF-KB signaling pathway.

Keywords: Subarachnoid hemorrhage, Early brain injury, Neuroinflammation, Fluoxetine

\footnotetext{
* Correspondence: d-chengao@zju.edu.cn

Department of Neurosurgery, The Second Affiliated Hospital of Zhejiang

University School of Medicine, Hangzhou, China
}

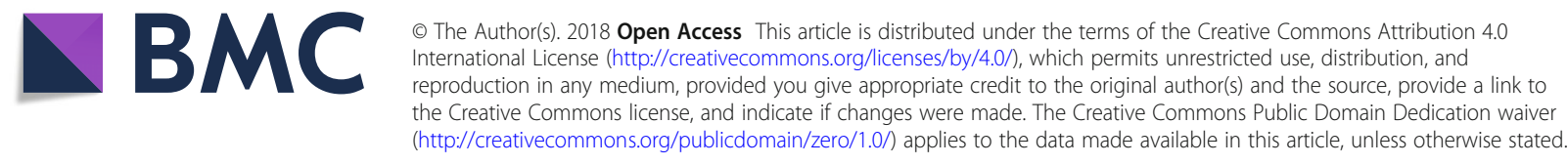




\section{Background}

Subarachnoid hemorrhage $(\mathrm{SAH})$ is a severe subtype of stroke with high mortality and morbidity; $25 \%$ of SAH patients died within 2 days, and cognitive and functional deficits present in about $20 \%$ of SAH survivors [1, 2]. In recent years, the importance of early brain injury has been concerned by researchers. Initial clinical severity after SAH has been shown to be the most important predictor for clinical outcomes in patients [3]. In addition, alleviating early brain injury has been reported to exert neuroprotective effects in $\mathrm{SAH}$ model [4-6].

Neuroinflammation is a well-recognized consequence of SAH and considered as an important contributor for early brain injury, cerebral vasospasm, and delayed brain injury after $\mathrm{SAH}[7,8]$. In addition, neuroinflammation is closely associated with functional outcome in SAH patients $[9,10]$. Toll-like receptors (TLRs) belong to a large family of pattern recognition receptors that play a key role in inflammatory responses [11]. Of all the TLR family members, TLR4 is widely expressed in the central nervous system, including microglia, neurons, astrocytes, endothelial cells [12]. After stimulation of TLR4 with ligands, the MyD88-dependent pathway activates NF- $\mathrm{kB}$, which produces pro-inflammatory cytokines mediators such as tumor necrosis factor (TNF- $\alpha$ ) [13]. Thus, therapies target TLR4 signaling pathway, and subsequent neuroinflammation may offer potential treatment to protect against neuroinflammation after $\mathrm{SAH}$.

Fluoxetine is one of the serotonin selective reuptake inhibitors. Since the least toxicity and side effects, fluoxetine has been widely prescribed depression and anxiety disorders [14]. Neuroprotective effects of fluoxetine have been demonstrated in different neurological diseases [15-18]. Fluoxetine has been shown to exert a capacity to regulate neuroinflammation [19, 20]. Our recent study also demonstrated that fluoxetine inhibited NLRP3 inflammasome activation and subsequent necrotic cell death in early brain injury after SAH [18]. Importantly, recent studies also demonstrated that fluoxetine inhibits TLR4 activation and subsequent NF- $\mathrm{kB}$ signaling pathway in vivo and in vitro [21-24]. In the present study, we investigated the effects of fluoxetine in neuroinflammation and the potential TLR4/MyD88/NF-KB signaling pathway in early brain injury after $\mathrm{SAH}$.

\section{Methods}

\section{Study design}

\section{Experiment 1}

Male SD rats were randomly divided into four groups: sham, sham+fluoxetine, SAH+vehicle, and SAH+fluoxetine group. Fluoxetine was purchased from Selleck and dissolved in sterile $0.9 \% \mathrm{NaCl}$. Fluoxetine $(10 \mathrm{mg} / \mathrm{kg})$ or vehicle was injected intravenously at $6 \mathrm{~h}$ after SAH induction as previously described [18]. SAH grade and neurological scores were measured in all groups. Brain edema ( $n=6$ /group), Evans blue extravasation $(n=6 /$ group), immunofluorescence/TUNEL staining $(n=5 /$ group), quantitative real-time polymerase chain reaction (qRT-PCR) $(n=5 /$ group), and western blot ( $n=6$ /group) were performed.

\section{Experiment 2}

Male SD rats were randomly divided into four groups: SAH+vehicle, SAH+TAK-242, and SAH+fluoxetine, SAH+fluoxetine+TAK-242 group. TAK-242 (1.5 mg/kg), an exogenous TLR4 antagonist, was injected intraperitoneally $1 \mathrm{~h}$ after SAH as previously described [25]. Neurological scores, Evans blue extravasation ( $n=6 /$ group), qRT-PCR ( $n=5$ /group), and western blot ( $n=6 /$ group) were performed.

\section{SAH model}

Male Sprague-Dawley (SD) rats were purchased from SLAC Laboratory Animal Company (Shanghai, China) and housed in a controlled humidity and temperature conditions. The endovascular perforation model was performed to induce rat SAH as previously described [26]. Briefly, we isolated the left carotid artery and its branches under anesthesia of pentobarbital $(50 \mathrm{mg} / \mathrm{kg})$. Then, we divided the external carotid artery (ECA) and advanced a 4-0 monofilament suture until resistance was felt. Subsequently, we punctured the vessel and induced $\mathrm{SAH}$. The sham rats underwent the same procedure without puncturing.

\section{SAH grade and neurological scores}

$\mathrm{SAH}$ grade and neurological scores were blindly assessed at $24 \mathrm{~h}$ after SAH as previously described [27]. Briefly, the basal cistern was divided into six segments. Each part was blindly obtained a grade from 0 to 3 judging by the amount of the blood clot in subarachnoid space. Then, the rats have received a total score ranging from 0 to 18 . Neurological scores were blindly evaluated with a modification of the Garcia scoring system [28]. This scoring system has six parts as follow: spontaneous activity, spontaneous movements of all limbs, movement of forelimbs, climbing wall of the wire cage, reaction to touch on both side of trunk, and response to vibrissae touch. Then, the rats have received a total score ranging from 3 to 18 . In this study, rats with $\mathrm{SAH}$ grade $<9$ were excluded.

\section{Brain edema and blood-brain barrier disruption}

Brain edema and blood-brain barrier (BBB) disruption were evaluated at $24 \mathrm{~h}$ after $\mathrm{SAH}$ as previously described 
[29]. Brain water content and Evans blue leakage were used to assessing brain edema and BBB disruption. Briefly, under deep anesthesia, rats were sacrificed. Then, brains were removed and divided into the left hemisphere, right hemisphere, cerebellum, and brainstem. The left hemispheres were weighed immediately to get the wet weight and dried at $105^{\circ} \mathrm{C}$ for 3 days to obtain dry weight. Brain water content was calculated as [(wet weight-dry weight)/wet weight] $\times 100 \%$. Evans blue dye $(2 \%, 5 \mathrm{ml} / \mathrm{kg})$ was administrated via the left femoral vein and circulated for $1 \mathrm{~h}$. Under deep anesthesia, rats were sacrificed by cardiac perfusion. Then, we removed and separated the brain to get the left hemispheres immediately. Subsequently, we weighted the brain samples and homogenized with $3 \mathrm{ml}$ of $50 \%$ trichloroacetic acid, then centrifuged at $15000 \mathrm{~g}$ for $30 \mathrm{~min}$. The supernatant was mixed with an equal volume of trichloroacetic acid with ethanol. After overnight incubation $\left(4{ }^{\circ} \mathrm{C}\right)$, the samples were centrifuged again $(15,000 \mathrm{~g}, 30 \mathrm{~min})$ and measured by spectrofluorophotometer (excitation wavelength $620 \mathrm{~nm}$ and emission wavelength $680 \mathrm{~nm}$ ).

\section{Quantitative real-time polymerase chain reaction}

The left basal cortical specimen (about 50-100 mg) in the face of the blood clot was collected for PCR detection at 24 h after SAH (as shown in Additional file 1: Figure S1). The total mRNA was then extracted using TRIzolTM Plus RNA Purification Kit (\#12183-555, Invitrogen, China). Then, we determined the quantity of the purified RNA using UV absorbance at $260 \mathrm{~nm}$. Subsequently, $1 \mu \mathrm{g}$ of purified RNA from each sample was reverse-transcribed to cDNA. Superscript ${ }^{\mathrm{TM}}$ III First-Stand Synthesis SuperMix for qRT-PCR (\#11752-050) was used to synthesize cDNA. The specific sequence of primers used was described as follows: TNF- $\alpha$ : sense primer 5 '-GGT CCC AAC AAG GAG GAG AAG TTC-3', antisense primer 5' -CCG CTT GGT GGT TTG CTA CGA C-3'; IL-1 $\beta$ : sense primer 5'-CGT GGG ATG ATG ACG ACC TGC-3', antisense primer 5'-GGA GAA TAC CAC TTG TTG GCT TAT-3'; IL-6: sense primer 5'-GAC AGC CAC TGC CTT CCC TAC TT-3', antisense primer 5'-CAG AAT TGC CAT TGC ACA ACT CT-3'; CD86: sense primer 5'-CAT CTA AGC AAG GAT ACC CGA AAC-3', and antisense primer $5^{\prime}$-GAG ATA GGC TGA TGG AGA CAC TGA A-3'. PCR amplification was performed with a program of $95^{\circ} \mathrm{C}$ for $1 \mathrm{~min}$, followed by 40 cycles of $95^{\circ} \mathrm{C}$ for $15 \mathrm{~s}$, and $63^{\circ} \mathrm{C}$ for $25 \mathrm{~s}$. The relative mRNA level of each target gene was calculated using the $2^{-\nabla \nabla C T}$ methods as previously described [30].

\section{Immunofluorescence staining}

Immunofluorescence staining was performed at $24 \mathrm{~h}$ after SAH as previously described [29]. Briefly, rats were deeply euthanized and perfused with $4 \%$ paraformaldehyde in
0.1-mM phosphate-buffered saline (PBS, PH7.4). Brain samples were immersed in $30 \%$ sucrose until sinking to the bottom; 18 um-thick slices were cut with a cryostat. The primary antibodies were polyclonal goat anti-Iba1(1:500, ab5076, Abcam), monoclonal mouse anti-NeuN (1:500, ab104224, Abcam), and polyclonal rabbit antiMPO (1:300, ab65871, Abcam). Alexa Fluor 594 donkey anti-goat IgG (1:500, Invitrogen) and donkey anti-mouse (1:500, Invitrogen) were used as secondary antibody. Terminal deoxynucleotide transferase-deoxyuridine triphosphate (dUTP) nick end labeling (TUNEL) was performed following the manufacturer's protocol (Roche, Switzerland). Finally, the slices were covered by DAPI and observed under a fluorescence microscope. All procedures were conducted by two investigators blind to the experimental condition.

To quantify Iba-1-positive, MPO-positive, TUNELpositive cells, we selected at least three sections per rats with similar areas of ipsilateral cortex (Additional file 1: Figure S1) and three fields with a magnification of $\times 200$ or $\times 400$ per section. For quantification of Iba-1-positive and MPO-positive cells, the numbers from these fields were averaged and expressed as positive cells per square millimeter for each mouse. For quantification of apoptotic neurons, the percentage of TUNEL-positive neurons was calculated as follows: (number of TUNELpositive neurons/total number of neurons) $\times 100 \%$. Tissue sections were analyzed by an observer who was blinded to the experimental cohorts.

\section{Western blot}

Western blot was performed at $24 \mathrm{~h}$ after $\mathrm{SAH}$ as previously described [26]. Under deep anesthesia, rats were sacrificed by cardiac perfusion with $0.1 \mathrm{M}$ PBS, then brains were removed and the left basal cortical specimens in the face of the blood clot were obtained. The nuclear proteins were prepared by the NE-PER nuclear extraction reagents (Thermo, Rockford). Briefly, the ipsilateral cortex was homogenized and centrifuged for $10 \mathrm{~min}\left(1000 \mathrm{~g}, 4^{\circ} \mathrm{C}\right)$. Total protein was determined by BCA Protein Assay Kit (Beyotime, Shanghai, China). An equal amount of protein (60 $\mu \mathrm{g}$ ) was suspended in loading buffer (denatured at $95^{\circ} \mathrm{C}$ for $5 \mathrm{~min}$ ) and loaded on an SDS-PAGE and transferred to nitrocellulose membranes. Then, we blocked the membranes with a nonfat dry milk buffer for $2 \mathrm{~h}$, followed by incubation overnight with the following primary antibodies: polyclonal rabbit anti-NF- $\mathrm{kB}$ p65 (1:1000, ab16502, Abcam), monoclonal mouse anti-TLR4 (1:200, sc-293,072, Santa Cruz Biotechnology), polyclonal rabbit anti-MyD88 (1:1000, ab2064, Abcam), monoclonal rabbit anti-MMP9 (1:5000, ab137867, Abcam), polyclonal rabbit anti-ZO-1 (1:2000, ab96587, Abcam); polyclonal goat anti-claudin-5 (1:500, sc-17,668, Santa Cruz Biotechnology), monoclonal rabbit anti-occludin (1:50000, ab167161, 
Abcam). The membranes were then incubated with horseradish peroxidase-conjugated secondary antibody for $1 \mathrm{~h}$ at room temperature. Blot bands were detected by X-ray film and quantified using Image J software (NIH).

\section{Statistical analysis}

Data were presented as mean \pm SD. For the data satisfying normal distribution, comparisons between groups were performed by one-way ANOVA as appropriate. For the data satisfying non-normal distribution, comparisons between groups were performed by Kruskal-Wallis test or Mann-Whitney test. Differences were considered significant at $p<0.05$. All statistical analyses were performed using GraphPad Prism and SPSS software.

\section{Results}

Physiological parameters, mortality, and SAH grade During the surgical procedures, no significant difference was observed in all physiological parameters including the mean arterial pressure, arterial $\mathrm{PH}, \mathrm{PO}_{2}, \mathrm{PCO}_{2}$, and

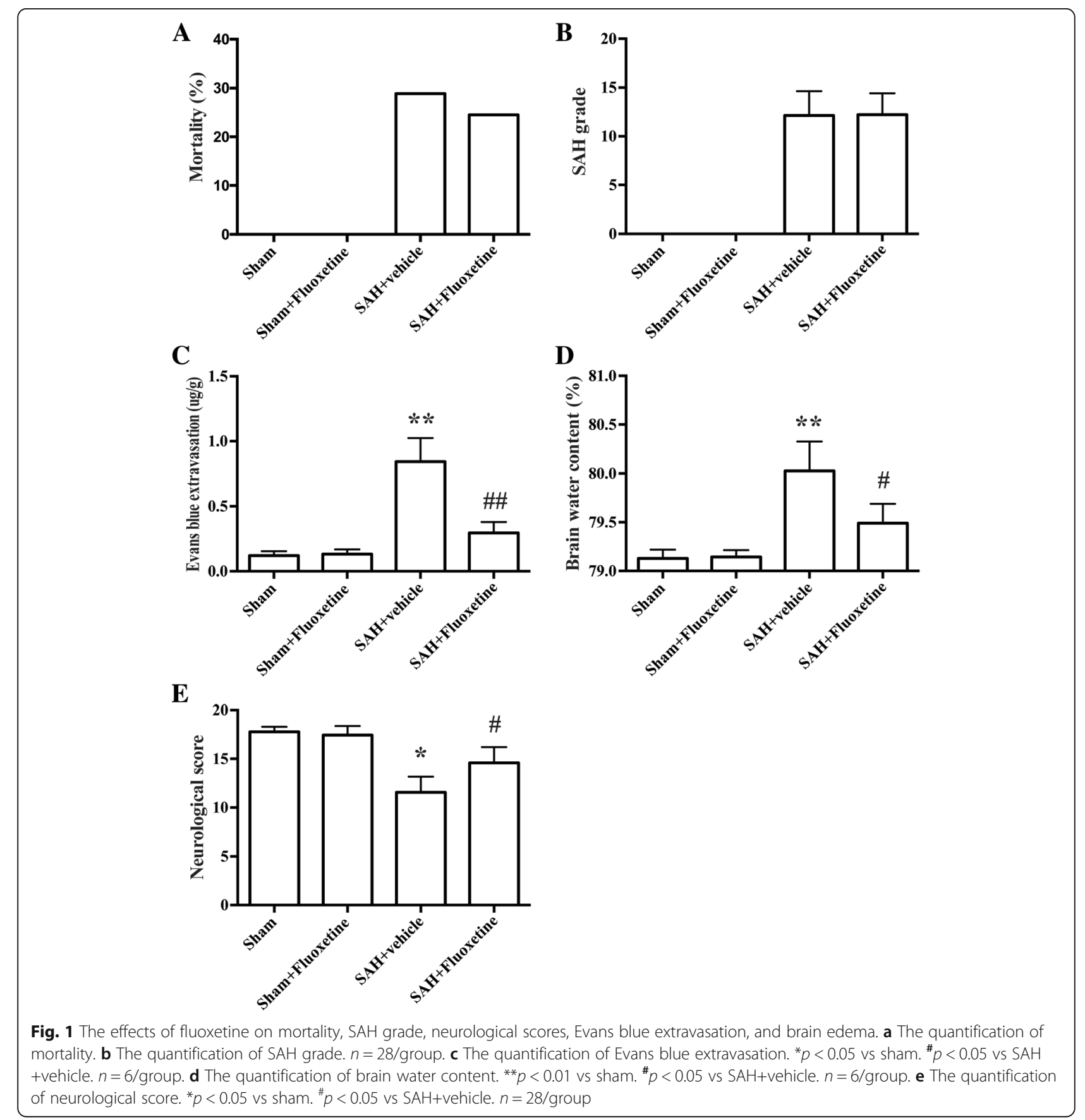


blood glucose levels (data not shown). None of the rats died in the sham and sham+fluoxetine group. In experiment 1 , the mortality of $\mathrm{SAH}+$ vehicle and $\mathrm{SAH}+$ fluoxetine group were $28.2 \%$ (11/39, Fig. 1a) and $24.5 \%$ (9/37, Fig. 1a), respectively. In experiment 2 , the mortality of $\mathrm{SAH}+$ vehicle, SAH+TAK-242, SAH+fluoxetine, and SAH +fluoxetine+TAK-242 group were $29.2 \%$ (7/24), 22.7\% (5/ 22), $22.7 \%(5 / 22)$, and $19.0 \%(4 / 21)$, respectively. SAH grade was blindly evaluated in our study. However, there is no significant difference between SAH groups $(p>0.05$, Fig. 1b).

\section{Fluoxetine attenuated BBB disruption, brain edema, and neurological deficits}

SAH induction increased the amount of Evans blue extravasation, indicating the disruption of $\mathrm{BBB}(p<0.01$,

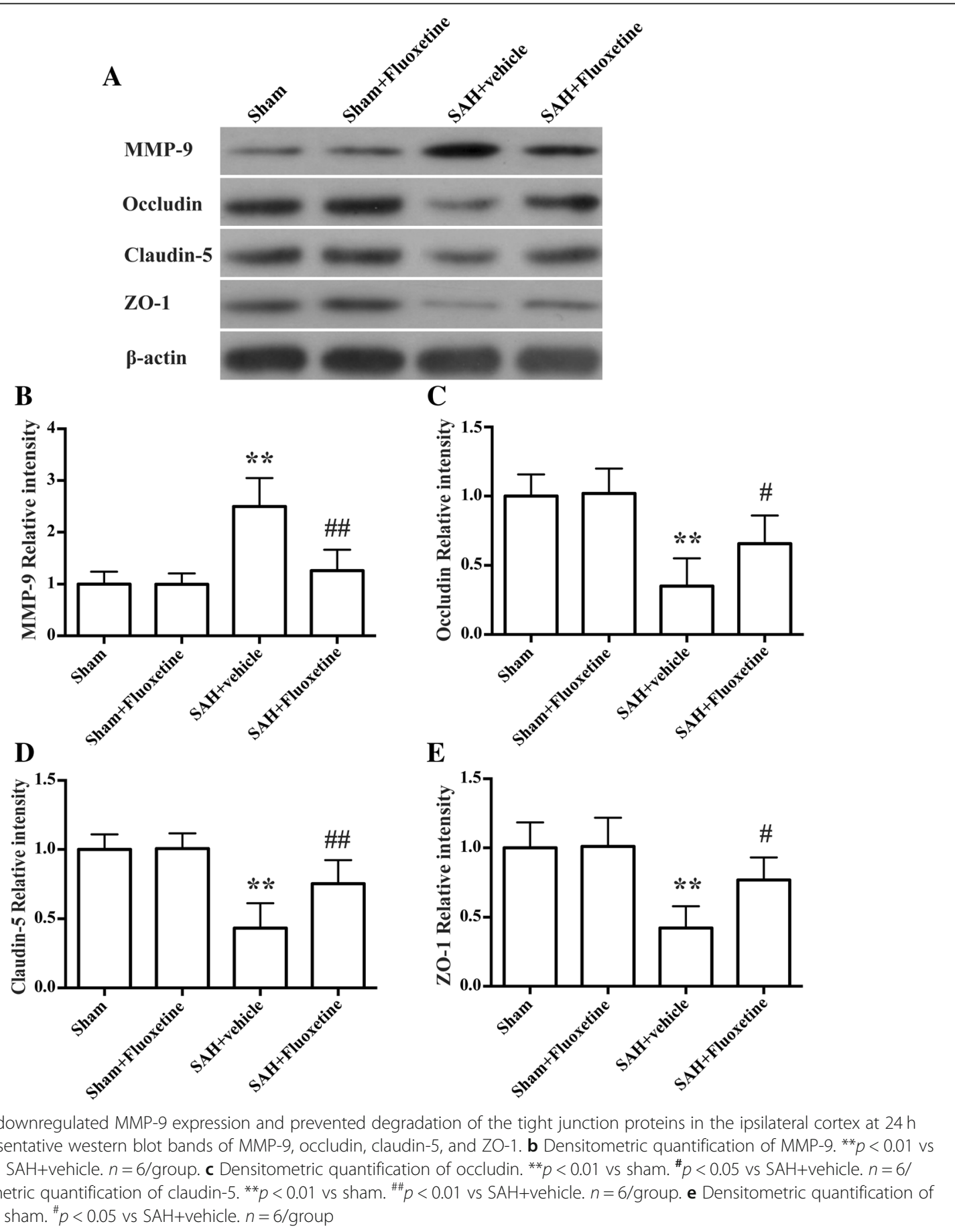

Fig. 2 Fluoxetine downregulated MMP-9 expression and prevented degradation of the tight junction proteins in the ipsilateral cortex at $24 \mathrm{~h}$ after SAH. a Representative western blot bands of MMP-9, occludin, claudin-5, and ZO-1. b Densitometric quantification of MMP-9. * $p<0.01$ vs sham. ${ }^{\# \#} p<0.01$ vs SAH+vehicle. $n=6$ /group. c Densitometric quantification of occludin. ${ }^{* *} p<0.01$ vs sham. ${ }^{*} p<0.05$ vs SAH+vehicle. $n=6 /$ group. d Densitometric quantification of claudin-5. ${ }^{* *} p<0.01$ vs sham. ${ }^{\# \#} p<0.01$ vs SAH+vehicle. $n=6 /$ group. e Densitometric quantification of ZO-1. ${ }^{* *} p<0.01$ vs sham. ${ }^{*} p<0.05$ vs SAH+vehicle. $n=6$ /group 
Fig. 1c). Similarly, SAH also increased the ratio of brain water content, indicating brain edema ( $p<0.01$, Fig. $1 \mathrm{~d})$. In addition, neurological scores were lower in the SAH +vehicle group than in the sham rats, indicating neurological impairments $(p<0.01$, Fig. 1e). The BBB disruption and brain edema were significantly attenuated by fluoxetine administration $(p<0.01$, Fig. $1 \mathrm{c}$ and $p<0.05$, Fig. 1d). Fluoxetine treatment also improved neurological function compared with the $\mathrm{SAH}+$ vehicle group $(p<0.05$, Fig. 1e).

\section{Fluoxetine downregulated MMP-9 expression and} decreased the degradation of tight junction proteins Rats in SAH+vehicle group had high levels of MMP-9 than control rats $(p<0.01$, Fig. 2a, b), and rats post-treated with fluoxetine had a lower MMP-9 expression $(p<0.01$, Fig. 2a, b). The protein levels of tight junction proteins, including occludin, claudin-5, and $\mathrm{ZO}-1$, were significantly decreased in the $\mathrm{SAH}+$ vehicle group when compared with the sham group $(p<0.01$,
Fig. 2 a, c-e), whereas fluoxetine treatment significantly upregulated their protein levels $(p<0.05$, Fig. $2 \mathrm{c}$, e, and $p<0.01$, Fig. 2d).

\section{Fluoxetine decreased the expression of pro-inflammatory cytokines}

qRT-PCR results showed the mRNA levels of pro-inflammatory cytokines TNF- $\alpha$, IL- $1 \beta$, IL- 6 , and CD86 were significantly increased in the $\mathrm{SAH}+$ vehicle group compared with the sham group $(p<0.01$, Fig. $3 \mathrm{a}-\mathrm{d})$, while fluoxetine administration significantly reduced the mRNA levels of TNF- $\alpha(p<0.01$, Fig. 3a), IL-1 $\beta(p<$ 0.05, Fig. 3b), IL-6 ( $p<0.01$, Fig. $3 \mathrm{c})$, and CD86 ( $p<0.01$, Fig. 3d).

Fluoxetine reduced lba-1-positive microglia/macrophages, neutrophil infiltration, and neuronal apoptosis

A significant increase of Iba-1positive cells was detected in $\mathrm{SAH}+$ vehicle group compared with the sham group $(p<0.01$, Fig. $4 \mathrm{a}, \mathrm{b})$, whereas fluoxetine
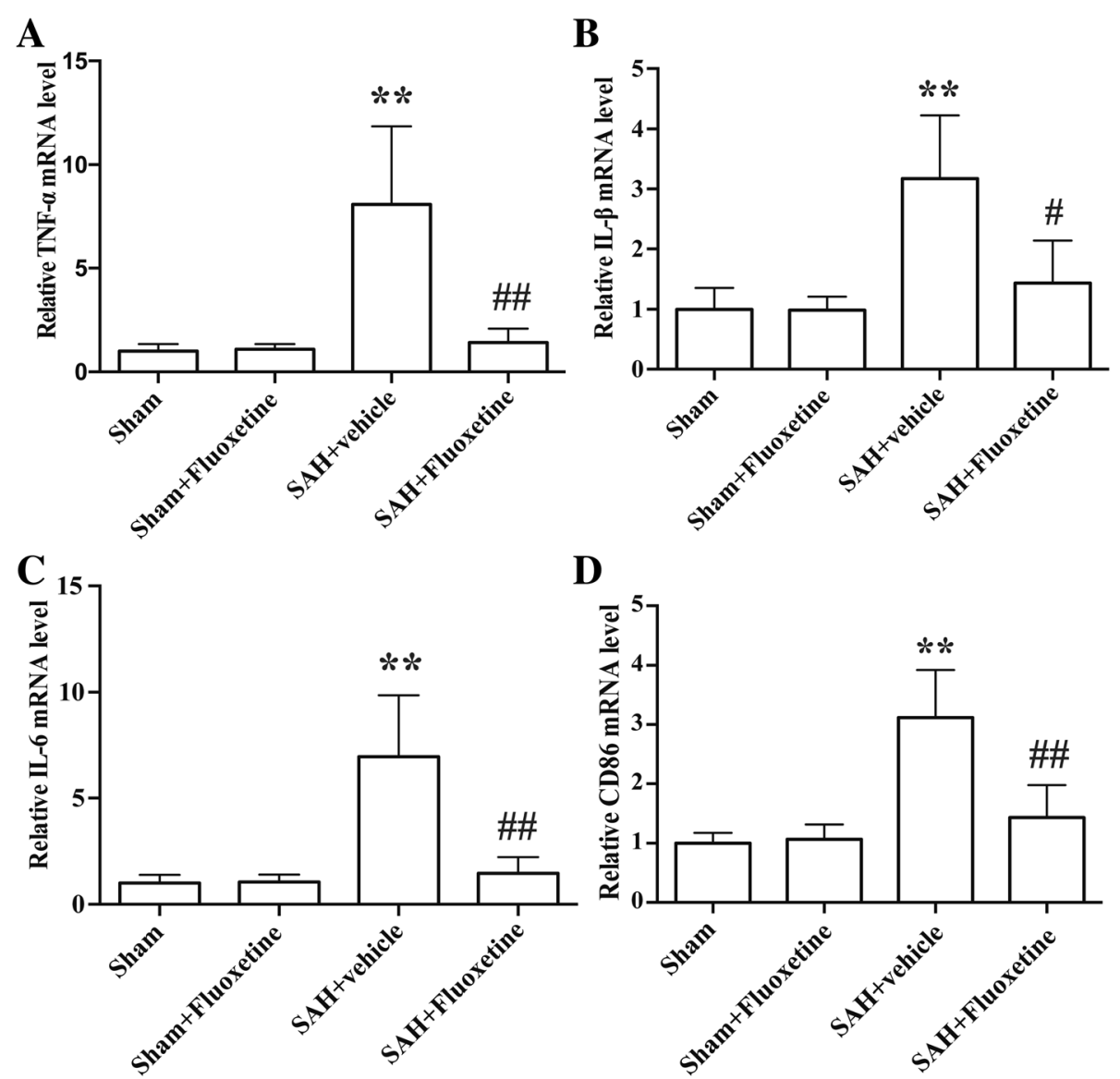

Fig. 3 Fluoxetine decreased the mRNA levels of pro-inflammatory cytokines. a The quantification of TNF-a mRNA levels. ${ }^{*} p<0.01$ vs sham. ${ }^{\# \#} p<0.01$ vs SAH+vehicle. $n=5$ /group. b The quantification of IL-1 $\beta$ mRNA levels. ${ }^{* *} p<0.01$ vs sham. ${ }^{*} p<0.05$ vs SAH + vehicle. $n$ =5/group. $\mathbf{c}$ The quantification of IL-6 mRNA levels. ${ }^{* *} p<0.01$ vs sham. ${ }^{\#} p<0.01$ vs SAH+vehicle. $n=5 /$ group. $\mathbf{d}$ The quantification of CD86 mRNA levels. ${ }^{* *} p<0.01$ vs sham. ${ }^{\# \#} p<0.01$ vs SAH+vehicle. $n=5 /$ group 


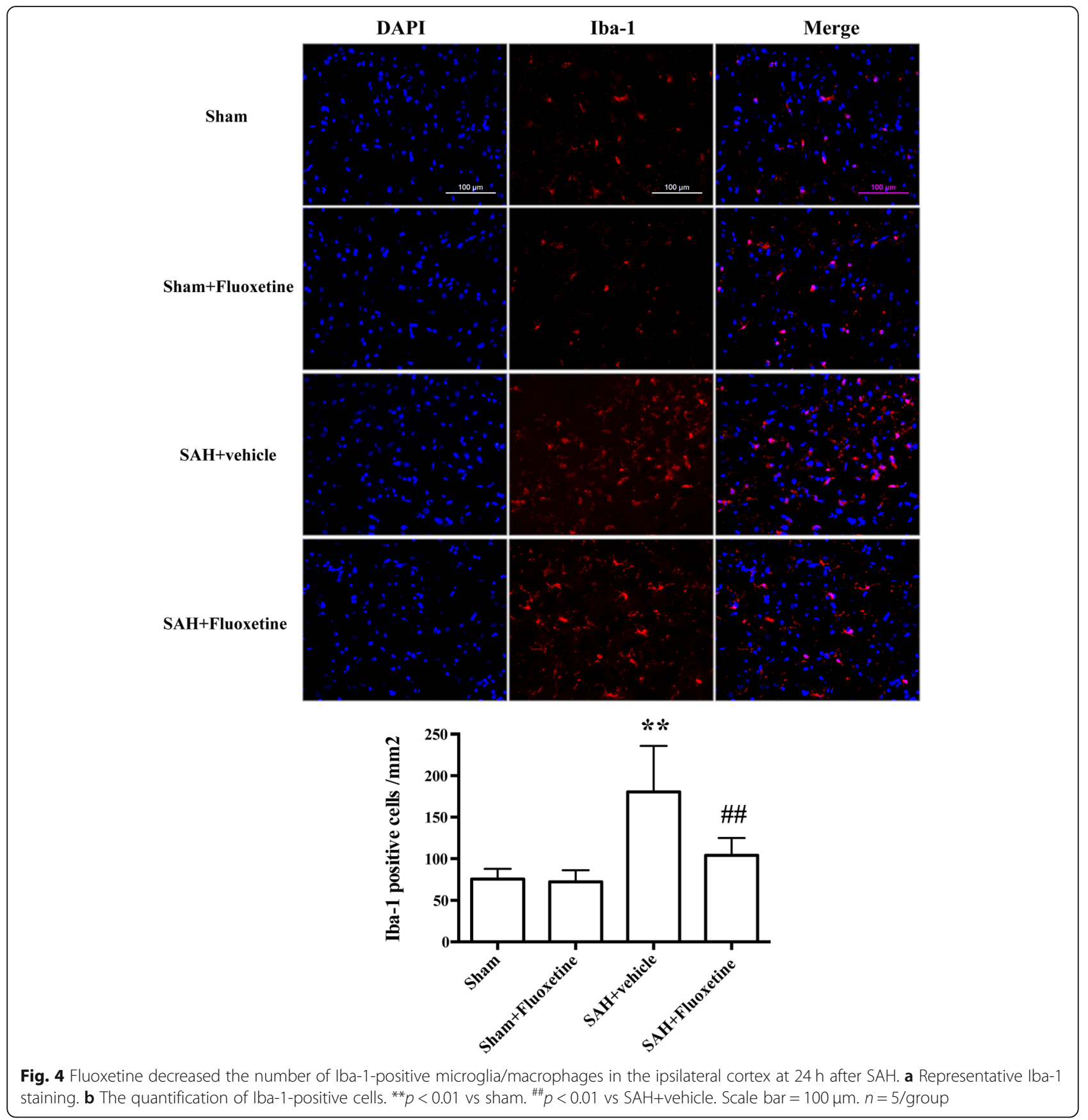

significantly decreased the number of Iba- 1 positive cells $(p<0.01$, Fig. 4a, b). MPO-positive cells markedly increased in the ipsilateral cortex after SAH when compared with the sham group ( $p<0.01$, Fig. $5 \mathrm{a}, \mathrm{b})$, while administration of fluoxetine significantly reduced the number of MPO-positive cells after SAH $(p<0.01$, Fig. $5 \mathrm{a}, \mathrm{b})$. The percentage of TUNEL-positive neurons was significantly higher in the $\mathrm{SAH}+$ vehicle group than the control group $(p<0.01$, Fig. 6a, b), whereas fluoxetine administration significantly decreased the percentage of TUNEL-positive neurons $(p<0.01$, Fig. 6a, b).
Fluoxetine attenuated TLR4 and MyD88 and reduced the nuclear translocation of NF-KB p65

The protein levels of TLR4 and MyD88 were significantly increased in the cortex in the $\mathrm{SAH}+$ vehicle group as compared with the sham group $(p<0.01$, Fig. $7 a-c)$. The protein levels of TLR4 and MyD88 in SAH+fluoxetine group were significantly lower than those of $\mathrm{SAH}$ +vehicle group $(p<0.01$, Fig. $7 \mathrm{a}-\mathrm{c})$. We also examined the nuclear levels of NF- $\mathrm{kB}$ p65, an indicator of the activation of the NF-kB signaling pathway. The protein levels of NF- $\mathrm{B}$ p p65 were significantly increased in the 


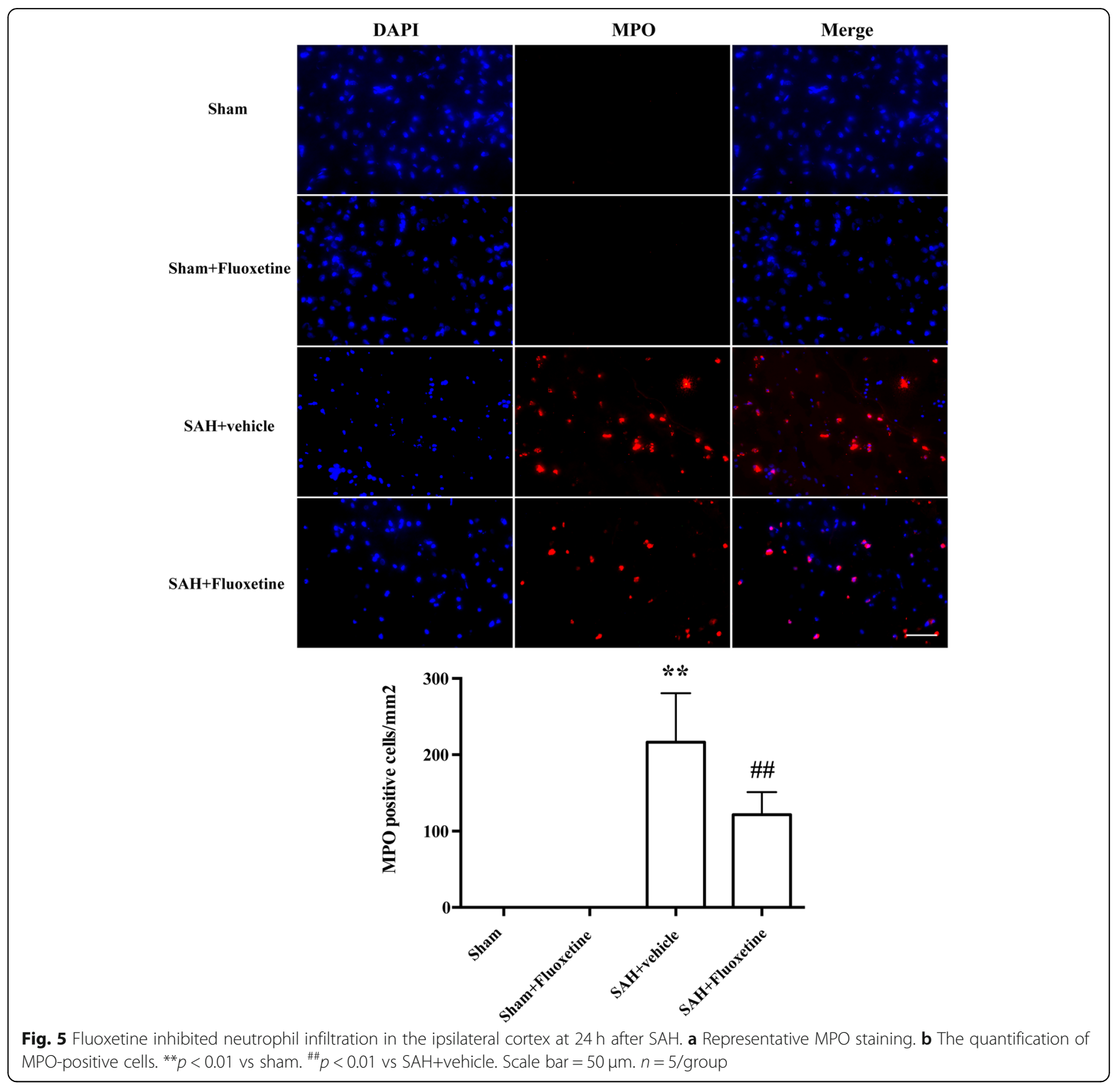

$\mathrm{SAH}+$ vehicle group as compared with the sham group $(p<0.01$, Fig. 7a, d). The protein levels of NF-kB p65 in $\mathrm{SAH}+$ fluoxetine group were significantly lower than those of SAH+vehicle group ( $p<0.01$, Fig. $7 \mathrm{a}, \mathrm{d})$.

\section{Combined administration of fluoxetine and TAK-242 did} not enhance the effects of fluoxetine in the expression of TLR4, MyD88, nuclear NF-KB, and pro-inflammatory cytokines, BBB disruption, and neurological function

The protein levels of TLR4, MyD88, and nuclear NF-kB were significantly decreased in the cortex in the $\mathrm{SAH}$ +TAK242, SAH+fluoxetine, and SAH+fluoxetine+TAK242 group as compared with the $\mathrm{SAH}+$ vehicle group $(p<0.01$, Fig. $8 \mathrm{a}-\mathrm{d})$. There was no significant difference between $\mathrm{SAH}+$ fluoxetine and $\mathrm{SAH}+$ fluoxetine +TAK-242 in proteins level of TLR4, MyD88, and nuclear NF-kB $(p>0.05$, Fig. $8 \mathrm{a}-\mathrm{d})$. The mRNA levels of pro-inflammatory cytokines TNF- $\alpha$, IL- $1 \beta$, and IL- 6 were significantly decreased in the cortex in the SAH + TAK242, SAH+fluoxetine, and SAH+fluoxetine+TAK242 group as compared with the $\mathrm{SAH}+$ vehicle group $(p<0.01$, Fig. 8e, $p<0.05$, Fig. 8 f, and $p<0.01$, Fig. 8g). No significant difference was observed in these mRNA levels between SAH+fluoxetine and SAH+fluoxetine+TAK-242 group ( $p>0.05$, Fig. $8 \mathrm{e}-\mathrm{g}$ ). Combined administration of fluoxetine and TAK-242 prevented the 


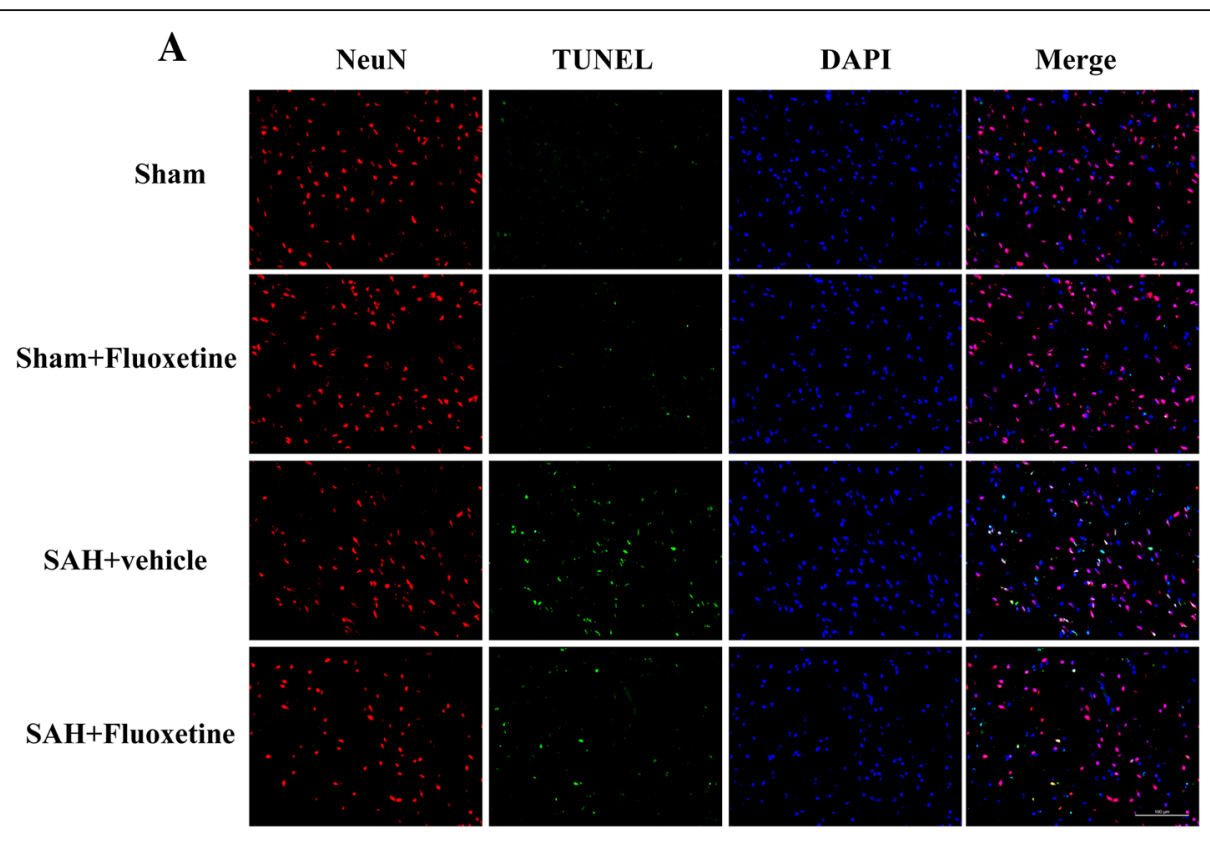

B

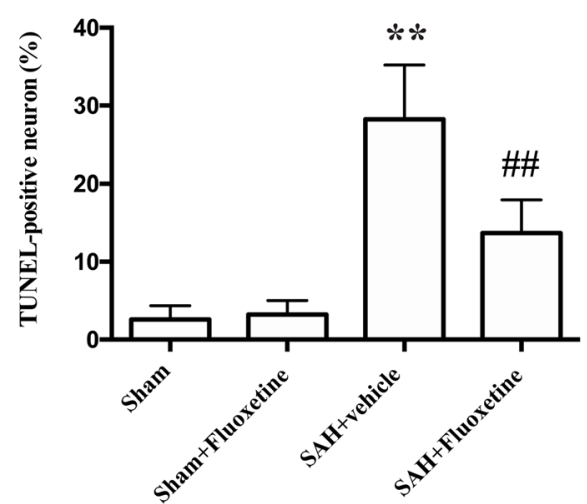

Fig. 6 Fluoxetine attenuated neuronal apoptosis in the ipsilateral cortex at $24 \mathrm{~h}$ after SAH. a Representative TUNEL staining. b The percentage of TUNEL-positive neurons. ${ }^{* *} p<0.01$ vs sham. ${ }^{\# \#} p<0.01$ vs SAH+vehicle. Scale bar $=100 \mu \mathrm{m} . n=5 /$ group

Evans blue extravasation $(p<0.01$, Fig. $8 \mathrm{~h})$ and improved the neurological function $(p<0.05$, Fig. $8 \mathrm{i})$, which was similar with fluoxetine treatment $(p>0.05$, Fig. 8h, i).

\section{Discussion}

The current study presented several novel findings:(1) fluoxetine attenuated BBB disruption, brain edema, and improved neurological function after SAH. (2) Fluoxetine alleviated the number of Iba-1-positive microglia/ macrophages, neutrophil infiltration, and cell death. (3) Fluoxetine reduced the levels of pro-inflammatory cytokines, and the underlying mechanisms, at least in part, involved the TLR4/MyD88/NF-KB signaling pathway (Fig. 9).

At present, no therapies are available to cure the neurological deficits in SAH patients [31]; however, an increasing number of studies show that inflammation contributes to early brain injury after SAH and inhibition of inflammation can ameliorate brain injury after SAH [10, 32-34]. One of the most important mediators in inflammation-induced brain injury after SAH is MMP-9. Notably, both clinical and basic studies have reported an elevation of MMP-9 in brain tissue, serum, and cerebrospinal fluid after SAH [35-37]. The MMP-9 elevation is responsible for the degradation of tight junction proteins, which are critical in the maintenance of BBB integrity. In the present study, we observed fluoxetine treatment alleviated MMP-9 expression and degradation of tight junction proteins (ZO-1, occludin, and claudin-5), attenuated BBB disruption and brain edema, and improved neurological function after SAH. The effects of fluoxetine on MMP-9 expression and subsequent BBB disruption were consistent with previous reports about fluoxetine treatment in experimental transient global ischemia and spinal cord injury $[38,39]$. BBB disruption facilitates infiltration of peripheral inflammatory cells, including macrophage and 

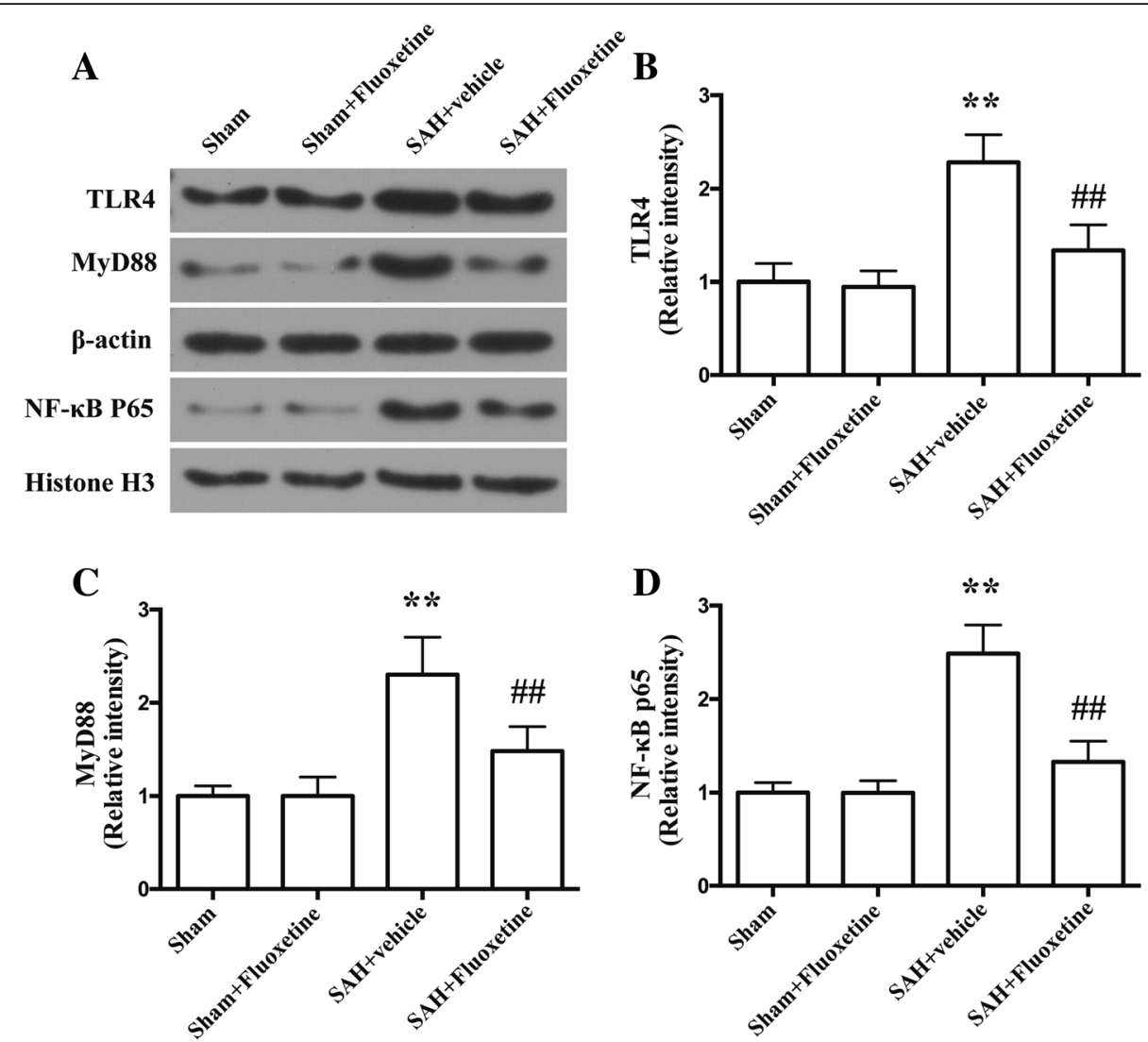

Fig. 7 Fluoxetine downregulated the protein levels of TLR4 and MyD88, but increased the nuclear protein levels of NF-KB p65 in the ipsilateral cortex at $24 \mathrm{~h}$ after SAH. a Representative western blot bands of TLR4, MyD88, and nuclear NF-kB p65. b Densitometric quantification of TLR4. ${ }^{* *} p<0.01$ vs sham. ${ }^{\# \#} p<0.01$ vs SAH+vehicle. $n=6 /$ group. $\mathbf{c}$ Densitometric quantification of MyD88. ${ }^{* *} p<0.01$ vs sham. ${ }^{\# \#} p<0.01$ vs SAH+vehicle. $n=6 /$ group. d Densitometric quantification of nuclear NF-KB p65. ${ }^{* *} p<0.01$ vs sham. ${ }^{\# \#} p<0.01$ vs SAH+vehicle. $n=6 /$ group

neutrophils, which aggravate neuroinflammation by releasing a multitude of inflammatory factors [40]. In addition, BBB disruption also results in neuronal cell death [38]. In the current study, we found that fluoxetine inhibited the neutrophils infiltration and reduced neural cell death in early brain injury after injury.

Inflammatory cytokines are important regulators in MMP-9 activation and subsequent BBB disruption. A previous study demonstrated that the selective inhibitor of IL-1 $\beta$ blocked JNK-mediated MMP-9 activation and improved neurological function in SAH rats [41]. IL-6 induced MMP-9 expression through the JAK-mediated pathway in macrophages [42]. TNF- $\alpha$ was also reported as an upstream regulator for MMP-9 [43]. In our study, we found that fluoxetine downregulated these inflammatory cytokines, which is in accordance with previous studies $[44,45]$. TLRs belong to a large family of pattern recognition receptors that play a key role in innate immunity and inflammatory responses. Of the TLR family members, TLR4 was of vital importance in this family. TLR4 is activated by many endogenous ligands such as heme, fibrinogen, heat shock proteins, all of which are produced after SAH [13, 46]. In fact, patients with aneurysmal SAH was reported to have higher TLR4 levels on peripheral blood mononuclear cells, which were associated with more massive $\mathrm{SAH}$, occurrence of cerebral vasospasm, delayed cerebral infarction, and worse functional recovery [47]. TLR4 interacts with two distinct adaptor proteins, MyD88 and Toll-receptor-associated activator of interferon (TRIF), and activates two parallel signaling pathways to initiate activation of transcription factors that regulate expression of proinflammatory cytokines genes [12]. In addition, the TRIFdependent pathway induces late phase activation of NF- $k B$, while the faster TLR4 route through MyD88 is the early activation of NF- $\mathrm{kB}$. Many previous studies have demonstrated the anti-inflammatory effects of fluoxetine in other system disorders in vivo and in vitro [20-24, 48]. In these studies, TLR4 and downstream NF- $\mathrm{B}$ were hotspots. However, limited studies focused on the effects of fluoxetine in the TLR4 signaling pathway after SAH. Therefore, we examined the TLR4mediated MyD88 pathway in the current study. Our results showed that the protein levels of TLR4 and 
A

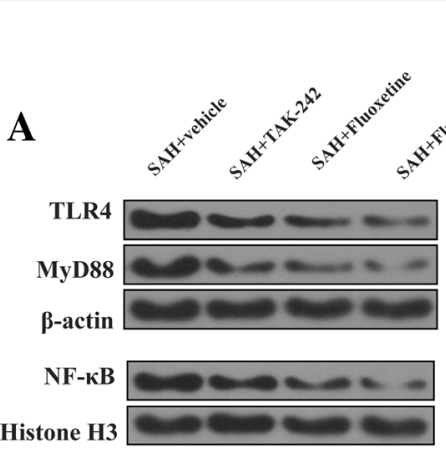

B

C
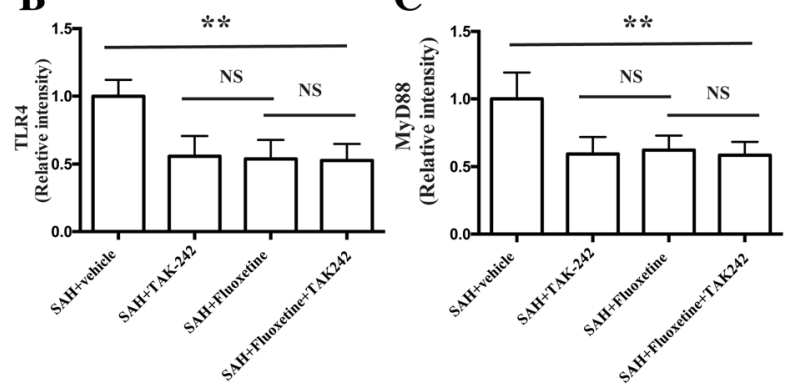

D
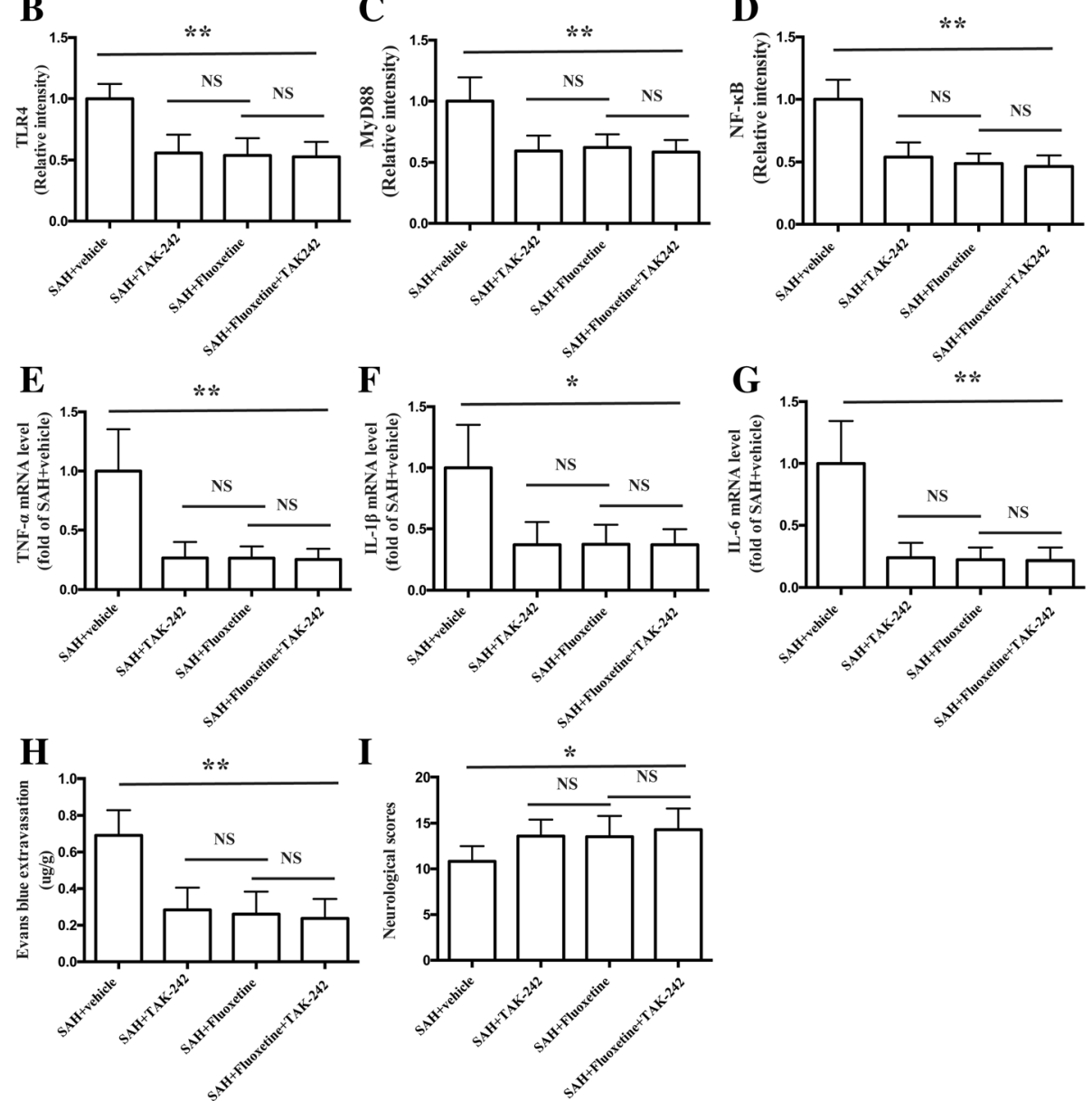

Fig. 8 Combined administration of fluoxetine and TAK-242 did not enhance the effects of fluoxetine in the expression of TLR4, MyD88, nuclear NF-KB, and pro-inflammatory cytokines, BBB disruption, and neurological function. a Representative western blot bands of TLR4, MyD88, and nuclear NF-KB p65. b Densitometric quantification of TLR4. ${ }^{* *} p<0.01$ vs SAH+vehicle. $n=6 /$ group. c Densitometric quantification of MyD88. ${ }^{* *} p<0.01$ vs SAH+vehicle. $n=6 /$ group. $\mathbf{d}$ Densitometric quantification of nuclear NF-KB p65. ${ }^{* *} p<0.01$ vs SAH+vehicle. $n=6 /$ group. e The quantification of TNF-a mRNA levels. ${ }^{* *} p<0.01$ vs SAH+vehicle. $n=5 /$ group $\mathbf{f}$ The quantification of $I L-1 \beta$ mRNA levels. ${ }^{*} p<0.05$ vs SAH+vehicle. $n=5 /$ group. g The quantification of IL-6 mRNA levels. ${ }^{* *} p<0.01$ vs SAH+vehicle. $n=5 /$ group. $\mathbf{h}$ The quantification of Evans blue extravasation. ${ }^{* *} p<0.01 v s$ SAH+vehicle. $n=6 /$ group. $\mathbf{i}$ The quantification of neurological score. ${ }^{*} p<0.05$ vs sham. ${ }^{*} p<0.05$ vs SAH + vehicle. $n=17 /$ group

MyD88 were significantly increased in early brain injury after SAH and fluoxetine downregulated their expression. In addition, we found that fluoxetine also reduced the nuclear translocation of NF-kB p65, an indicator of $\mathrm{NF}-\mathrm{kB}$ activation. What is more important is that we also used TAK-242, a small-molecule inhibitor of the TLR4 signaling pathway. We found that the combined administration of fluoxetine and TAK-242 reduced the expression of TLR4, MyD88, and nuclear NF-кB, decreased the mRNA levels of pro-inflammatory cytokines, 


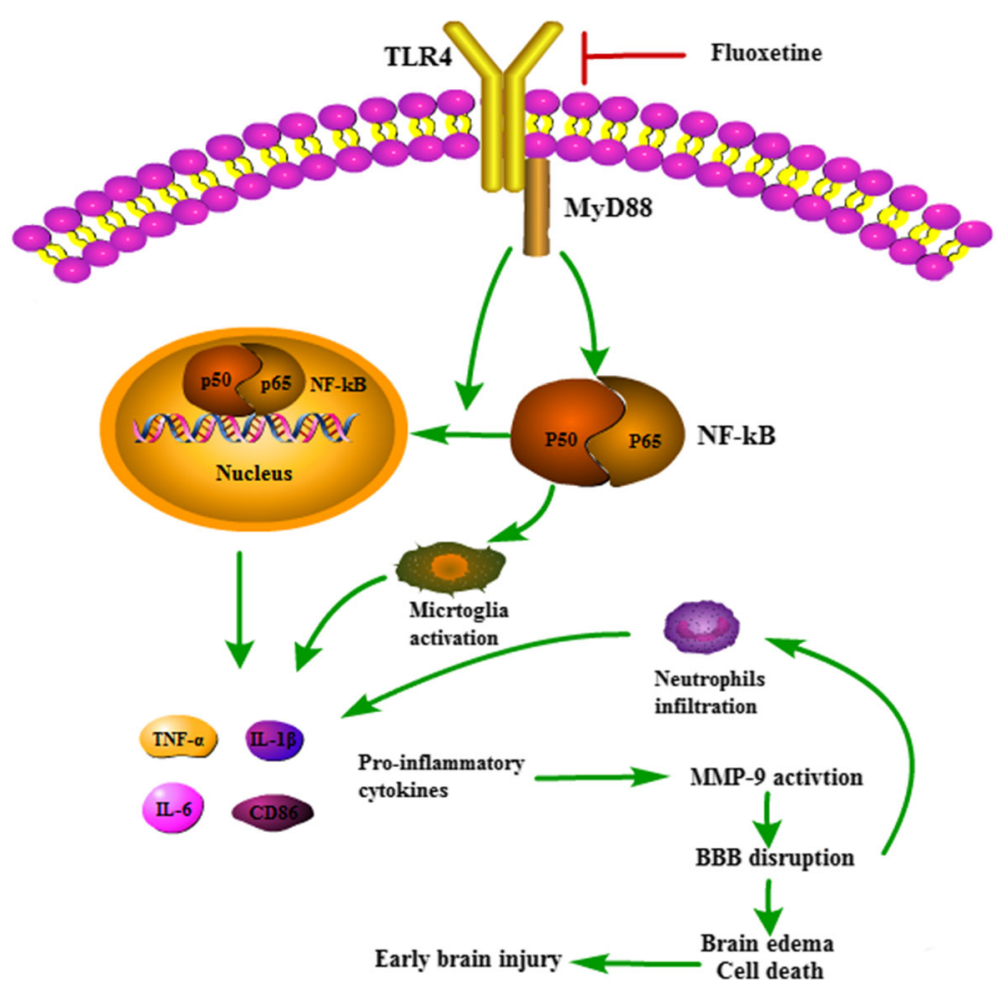

Fig. 9 The potential molecular mechanisms of anti-inflammatory effects of fluoxetine through TLR4/MyD88/NF-KB signaling pathway

prevented BBB disruption, and improved neurological function after SAH. These beneficial effects of combined administration were similar to alone fluoxetine treatment. Taken together, our study indicated that TLR4/ MyD88/NF-kB signaling pathway was involved in antiinflammatory effects of fluoxetine in early brain injury after SAH.

There are some limitations in our study. First, the present study aimed at investigating the effects and potential mechanism of fluoxetine in neuroinflammation in early brain injury after $\mathrm{SAH}$, the long-term study of fluoxetine after SAH is still needed in the future. Second, previous studies showed anti-apoptotic effects of fluoxetine, which did not deeply evaluate in the current study.

\section{Conclusions}

The current study has demonstrated that fluoxetine attenuated neuroinflammation and improved neurological function after SAH. The potential mechanisms involved, at least in part, TLR4/MyD88/NF-kB signaling pathway.

\section{Additional file}

Additional file 1: Figure S1. Representative pictures of brains in $\mathrm{SAH}$ group showing the sample region. (TIF $372 \mathrm{~kb}$ )

\section{Abbreviations}

BBB: Blood-brain barrier; ECA: External carotid artery; IL-1 $\beta$ : Interleukin-1 $\beta$; IL6: Interleukin-6; MMP-9: Matrix metallopeptidase 9; MPO: Myeloperoxidase; MyD88: Myeloid differentiation primary response 88; NF-KB: Nuclear factor kappa B; GRT-PCR: Quantitative real-time polymerase chain reaction; SAH: Subarachnoid hemorrhage; SD: Sprague-Dawley; TLRs: Toll-like receptors; TNF-a: Tumor necrosis factor-a; TUNEL: Terminal deoxynucleotidyl transferase dUTP nick end labeling

Acknowledgements

Not applicable.

Funding

This work was supported by the National Natural Science Foundation of China (NO.81771246, 81571106, 81701152), Natural Science Foundation of Zhejiang province (LY17H090008, LY17H090007 and Y18H090019).

Availability of data and materials

All data supporting the conclusions of this article are included with this article.

\section{Authors' contributions}

This work includes significant contributions from all authors. GC and FYL conceived the study and contributed to its experimental design. JC, CW, WR, HZP, GPG, and JRL carried out the laboratory experiments, CQ, JSC, GPG, and LW analyzed the data. FYL, JC, and GC wrote the manuscript. CW and GC contributed to the editing of the manuscript. All authors read and approved the final manuscript.

Ethics approval and consent to participate

All experimental protocols and procedures were approved by the Institutional Animal Care and Use Committee of Zhejiang University and carried out in accordance with the Guide for the Care and Use of Laboratory Animals of the National Institutes of Health. 


\section{Consent for publication}

Not applicable.

\section{Competing interests}

The authors declare that they have no competing interests.

\section{Publisher's Note}

Springer Nature remains neutral with regard to jurisdictional claims in published maps and institutional affiliations.

Received: 19 April 2018 Accepted: 3 December 2018 Published online: 20 December 2018

\section{References}

1. Connolly ES Jr, Rabinstein AA, Carhuapoma JR, Derdeyn CP, Dion J, Higashida RT, Hoh BL, Kirkness CJ, Naidech AM, Ogilvy CS, et al. Guidelines for the management of aneurysmal subarachnoid hemorrhage: a guideline for healthcare professionals from the American Heart Association/American Stroke Association. Stroke. 2012;43:1711-37.

2. Springer MV, Schmidt JM, Wartenberg KE, Frontera JA, Badjatia N, Mayer SA. Predictors of global cognitive impairment 1 year after subarachnoid hemorrhage. Neurosurgery. 2009;65:1043-50 discussion 1050-1041.

3. Mocco J, Ransom ER, Komotar RJ, Schmidt JM, Sciacca RR, Mayer SA, Connolly ES Jr. Preoperative prediction of long-term outcome in poor-grade aneurysmal subarachnoid hemorrhage. Neurosurgery. 2006;59:529-38 discussion 529-538.

4. Zhang X, Wu Q, Zhang Q, Lu Y, Liu J, Li W, Lv S, Zhou M, Zhang X, Hang C. Resveratrol attenuates early brain injury after experimental subarachnoid hemorrhage via inhibition of NLRP3 inflammasome activation. Front Neurosci. 2017;11:611

5. Fan R, Enkhjargal B, Camara R, Yan F, Gong L, ShengtaoYao TJ, Chen Y, Zhang $\mathrm{JH}$. Critical role of EphA4 in early brain injury after subarachnoid hemorrhage in rat. Exp Neurol. 2017;296:41-8.

6. Liu L, Kawakita F, Fujimoto M, Nakano F, Imanaka-Yoshida K, Yoshida T, Suzuki $\mathrm{H}$. Role of periostin in early brain injury after subarachnoid hemorrhage in mice. Stroke. 2017:48:1108-11.

7. Suzuki H, Kawakita F. Tenascin- $\mathrm{C}$ in aneurysmal subarachnoid hemorrhage: deleterious or protective? Neural Regen Res. 2016;11:230-1.

8. Schneider UC, Schiffler J, Hakiy N, Horn P, Vajkoczy P. Functional analysis of pro-inflammatory properties within the cerebrospinal fluid after subarachnoid hemorrhage in vivo and in vitro. $J$ Neuroinflammation. 2012;9:28.

9. Niwa A, Osuka K, Nakura T, Matsuo N, Watabe T, Takayasu M. Interleukin-6, MCP-1, IP-10, and MIG are sequentially expressed in cerebrospinal fluid after subarachnoid hemorrhage. J Neuroinflammation. 2016;13:217.

10. Lucke-Wold BP, Logsdon AF, Manoranjan B, Turner RC, McConnell E, Vates GE, Huber JD, Rosen CL, Simard JM. Aneurysmal subarachnoid hemorrhage and neuroinflammation: a comprehensive review. Int J Mol Sci. 2016:17:497.

11. De Nardo D. Toll-like receptors: activation, signalling and transcriptional modulation. Cytokine. 2015;74:181-9.

12. Buchanan MM, Hutchinson M, Watkins LR, Yin H. Toll-like receptor 4 in CNS pathologies. J Neurochem. 2010;114:13-27.

13. Kawakita F, Fujimoto M, Liu L, Nakano F, Nakatsuka Y, Suzuki H. Effects of toll-like receptor 4 antagonists against cerebral vasospasm after experimental subarachnoid hemorrhage in mice. Mol Neurobiol. 2017;54: 6624-33.

14. Wong DT, Bymaster FP, Engleman EA. Prozac (fluoxetine, Lilly 110140), the first selective serotonin uptake inhibitor and an antidepressant drug: twenty years since its first publication. Life Sci. 1995;57:411-41.

15. Khodanovich M, Kisel A, Kudabaeva M, Chernysheva G, Smolyakova V, Krutenkova E, Wasserlauf I, Plotnikov M, Yarnykh V. Effects of fluoxetine on hippocampal neurogenesis and neuroprotection in the model of global cerebral ischemia in rats. Int J Mol Sci. 2018;19(1):162.

16. Lee JY, Choi HY, Yune TY. Fluoxetine and vitamin C synergistically inhibits blood-spinal cord barrier disruption and improves functional recovery after spinal cord injury. Neuropharmacology. 2016;109:78-87.

17. Lee JY, Kang SR, Yune TY. Fluoxetine prevents oligodendrocyte cell death by inhibiting microglia activation after spinal cord injury. J Neurotrauma. 2015;32:633-44.

18. Li JR, Xu HZ, Nie S, Peng YC, Fan LF, Wang ZJ, Wu C, Yan F, Chen JY, Gu C, et al. Fluoxetine-enhanced autophagy ameliorates early brain injury via inhibition of NLRP3 inflammasome activation following subarachnoid hemorrhage in rats. J Neuroinflammation. 2017;14:186.

19. Alboni S, Poggini S, Garofalo S, Milior G, El Hajj H, Lecours C, Girard I, Gagnon S, Boisjoly-Villeneuve S, Brunello N, et al. Fluoxetine treatment affects the inflammatory response and microglial function according to the quality of the living environment. Brain Behav Immun. 2016;58:261-71.

20. Liechti FD, Grandgirard D, Leib SL. The antidepressant fluoxetine protects the hippocampus from brain damage in experimental pneumococcal meningitis. Neuroscience. 2015;297:89-94.

21. Koh SJ, Kim JM, Kim IK, Kim N, Jung HC, Song IS, Kim JS. Fluoxetine inhibits NF-kappaB signaling in intestinal epithelial cells and ameliorates experimental colitis and colitis-associated colon cancer in mice. Am J Physiol Gastrointest Liver Physiol. 2011;301:G9-19.

22. Zhang F, Zhou H, Wilson BC, Shi JS, Hong JS, Gao HM. Fluoxetine protects neurons against microglial activation-mediated neurotoxicity. Parkinsonism Relat Disord. 2012;18(Suppl 1):S213-7.

23. Ha E, Jung KH, Choe BK, Bae JH, Shin DH, Yim SV, Baik HH. Fluoxetine increases the nitric oxide production via nuclear factor kappa B-mediated pathway in BV2 murine microglial cells. Neurosci Lett. 2006;397:185-9.

24. Waiskopf N, Ofek K, Gilboa-Geffen A, Bekenstein U, Bahat A, Bennett ER, Podoly E, Livnah O, Hartmann G, Soreq H. AChE and RACK1 promote the anti-inflammatory properties of fluoxetine. J Mol Neurosci. 2014;53:306-15.

25. Hua F, Tang H, Wang J, Prunty MC, Hua X, Sayeed I, Stein DG. TAK-242, an antagonist for Toll-like receptor 4, protects against acute cerebral ischemia/ reperfusion injury in mice. J Cereb Blood Flow Metab. 2015;35:536-42.

26. Li J, Chen J, Mo H, Chen J, Qian C, Yan F, Gu C, Hu Q, Wang L, Chen G. Minocycline protects against NLRP3 inflammasome-induced inflammation and P53-associated apoptosis in early brain injury after subarachnoid hemorrhage. Mol Neurobiol. 2016;53:2668-78.

27. Ying GY, Jing CH, Li JR, Wu C, Yan F, Chen JY, Wang L, Dixon BJ, Chen G. Neuroprotective effects of valproic acid on blood-brain barrier disruption and apoptosis-related early brain injury in rats subjected to subarachnoid hemorrhage are modulated by heat shock protein $70 /$ matrix metalloproteinases and heat shock protein 70/AKT pathways. Neurosurgery. 2016;79:286-95.

28. Chen J, Wang L, Wu C, Hu Q, Gu C, Yan F, Li J, Yan W, Chen G. Melatoninenhanced autophagy protects against neural apoptosis via a mitochondrial pathway in early brain injury following a subarachnoid hemorrhage. J Pineal Res. 2014;56:12-9.

29. Xu H, Li J, Wang Z, Feng M, Shen Y, Cao S, Li T, Peng Y, Fan L, Chen J, et al. Methylene blue attenuates neuroinflammation after subarachnoid hemorrhage in rats through the Akt/GSK-3beta/MEF2D signaling pathway. Brain Behav Immun. 2017:65:125-39.

30. Livak KJ, Schmittgen TD. Analysis of relative gene expression data using real-time quantitative PCR and the 2(-Delta Delta C(T)) method. Methods. 2001;25:402-8.

31. Young AM, Karri SK, Helmy A, Budohoski KP, Kirollos RW, Bulters DO, Kirkpatrick PJ, Ogilvy CS, Trivedi RA. Pharmacologic management of subarachnoid hemorrhage. World Neurosurg. 2015;84:28-35.

32. Savarraj JPJ, Parsha K, Hergenroeder GW, Zhu L, Bajgur SS, Ahn S, Lee K, Chang T, Kim DH, Liu Y, Choi HA. Systematic model of peripheral inflammation after subarachnoid hemorrhage. Neurology. 2017;88: 1535-45.

33. Frontera JA, Provencio JJ, Sehba FA, McIntyre TM, Nowacki AS, Gordon E, Weimer $\mathrm{JM}$, Aledort $\mathrm{L}$. The role of platelet activation and inflammation in early brain injury following subarachnoid hemorrhage. Neurocrit Care. 2017; 26:48-57.

34. You W, Wang Z, Li H, Shen H, Xu X, Jia G, Chen G. Inhibition of mammalian target of rapamycin attenuates early brain injury through modulating microglial polarization after experimental subarachnoid hemorrhage in rats. J Neurol Sci. 2016;367:224-31.

35. Feiler S, Plesnila N, Thal SC, Zausinger S, Scholler K. Contribution of matrix metalloproteinase-9 to cerebral edema and functional outcome following experimental subarachnoid hemorrhage. Cerebrovasc Dis. 2011;32:289-95

36. Fischer M, Dietmann A, Beer R, Broessner G, Helbok R, Pfausler B, Schmutzhard E, Lackner P. Differential regulation of matrixmetalloproteinases and their tissue inhibitors in patients with aneurysmal subarachnoid hemorrhage. PLoS One. 2013:8:e59952.

37. Triglia T, Mezzapesa A, Martin JC, Verdier M, Lagier D, Dufour H, Bruder N, Alessi MC, Velly LJ. Early matrix metalloproteinase-9 concentration in the first 
$48 \mathrm{~h}$ after aneurysmal subarachnoid haemorrhage predicts delayed cerebral ischaemia: an observational study. Eur J Anaesthesiol. 2016;33:662-9.

38. Lee JY, Lee HE, Kang SR, Choi HY, Ryu JH, Yune TY. Fluoxetine inhibits transient global ischemia-induced hippocampal neuronal death and memory impairment by preventing blood-brain barrier disruption. Neuropharmacology. 2014;79:161-71.

39. Lee JY, Kim HS, Choi HY, Oh TH, Yune TY. Fluoxetine inhibits matrix metalloprotease activation and prevents disruption of blood-spinal cord barrier after spinal cord injury. Brain. 2012;135:2375-89.

40. Obermeier B, Daneman R, Ransohoff RM. Development, maintenance and disruption of the blood-brain barrier. Nat Med. 2013;19:1584-96.

41. Sozen T, Tsuchiyama R, Hasegawa Y, Suzuki H, Jadhav V, Nishizawa S, Zhang $J$ H. Role of interleukin-1 beta in early brain injury after subarachnoid hemorrhage in mice. Stroke. 2009;40:2519-25.

42. Kothari P, Pestana R, Mesraoua R, Elchaki R, Khan KM, Dannenberg AJ Falcone DJ. IL-6-mediated induction of matrix metalloproteinase-9 is modulated by JAK-dependent IL-10 expression in macrophages. J Immunol. 2014;192:349-57.

43. Xue H, Sun K, Xie W, Hu G, Kong H, Wang Q, Wang H. Etanercept attenuates short-term cigarette-smoke-exposure-induced pulmonary arterial remodelling in rats by suppressing the activation of TNF-a/NF-kB signal and the activities of MMP-2 and MMP-9. Pulm Pharmacol Ther. 2012;25:208-15

44. Aksu U, Guner I, Yaman OM, Erman H, Uzun D, Sengezer-Inceli M, Sahin A, Yelmen N, Gelisgen R, Uzun H, Sahin G. Fluoxetine ameliorates imbalance of redox homeostasis and inflammation in an acute kidney injury model. J Physiol Biochem. 2014;70:925-34.

45. Yang JM, Rui BB, Chen C, Chen H, Xu TJ, Xu WP, Wei W. Acetylsalicylic acid enhances the anti-inflammatory effect of fluoxetine through inhibition of NF-kappaB, p38-MAPK and ERK1/2 activation in lipopolysaccharide-induced BV-2 microglia cells. Neuroscience. 2014;275:296-304.

46. Fang H, Wang PF, Zhou Y, Wang YC, Yang QW. Toll-like receptor 4 signaling in intracerebral hemorrhage-induced inflammation and injury. J Neuroinflammation. 2013;10:27.

47. Ma C, Zhou W, Yan Z, Qu M, Bu X. Toll-like receptor 4 (TLR4) is associated with cerebral vasospasm and delayed cerebral ischemia in aneurysma subarachnoid hemorrhage. Neurol Med Chir (Tokyo). 2015;55:878-84.

48. Habib M, Shaker S, El-Gayar N, Aboul-Fotouh S. The effects of antidepressants "fluoxetine and imipramine" on vascular abnormalities and Toll like receptor-4 expression in diabetic and non-diabetic rats exposed to chronic stress. PLoS One. 2015;10:e0120559.

Ready to submit your research? Choose BMC and benefit from:

- fast, convenient online submission

- thorough peer review by experienced researchers in your field

- rapid publication on acceptance

- support for research data, including large and complex data types

- gold Open Access which fosters wider collaboration and increased citations

- maximum visibility for your research: over $100 \mathrm{M}$ website views per year

At BMC, research is always in progress.

Learn more biomedcentral.com/submissions 